\title{
Spatial organization and social relations in a reintroduced population of Endangered Iberian lynx Lynx pardinus
}

\author{
Pedro Sarmento, Carlos Carrapato, Catarina Eira and Joño Paulo Silva
}

\begin{abstract}
In 2015 10 Iberian lynxes Lynx pardinus were released in south-eastern Portugal, within the framework of a Spanish-Portuguese reintroduction project. We examined each individual's use of space and social interactions during the first year after their release. Lynxes were selected for reintroduction according to behavioural, genetic and health criteria and fitted with collars with VHF and global positioning systems. Both males and females went through an exploratory phase that lasted 65-105 days. The lynxes did not exhibit any movement directionality from the release site during the exploratory period. During AugustDecember 2015 a stable nucleus comprising seven individuals (four males, three females) was established south-west of the release enclosure. Although the males had a slightly larger mean home range $\left(11.18 \pm \mathrm{SE} 1.36 \mathrm{~km}^{2}\right)$ than females $\left(9.87 \pm \mathrm{SE} 8.71 \mathrm{~km}^{2}\right)$, the difference was not significant. The knowledge obtained during the first year of the lynx reintroduction project in Portugal is critical to support the future of this reintroduction strategy. Our results suggest that once the soft release technique is no longer possible because of logistical constraints on the construction of more enclosures, new individuals should be released in unoccupied areas surrounded by occupied territories. This will promote strong social ties to the resident population and prevent lynx dispersal.
\end{abstract}

Keywords Dispersal, EU Life project, home range, lynx, population monitoring, soft release, territoriality

Supplementary material for this article can be found online at https://doi.org/10.1017/So030605317000370

Pedro Sarmento (Corresponding author) and Carlos Carrapato Instituto da Conservação da Natureza e das Florestas, Centro Polivalente de Divulgação da Casa do Lanternim, Rua D. Sancho II, no 15 | 7750-350 Mértola, Portugal E-mail sarmentop@gmail.com

Catarina Eira Departamento de Biologia \& Centro de Estudos do Ambiente e do Mar, University of Aveiro, Aveiro, Portugal

JoÃo Paulo Silva Research Centre in Biodiversity and Genetic Resources/ Research Network in Environmental and Evolutionary Biology Associate Laboratory, University of Porto, Vairão, Portugal, and Centre for Applied Ecology Professor Baeta Neves/Research Network in Environmental and Evolutionary Biology Associate Laboratory, University of Lisbon, Lisbon, Portugal

Received 3 November 2016. Revision requested 5 January 2017.

Accepted 7 March 2017. First published online 6 July 2017.

\section{Introduction}

The Iberian lynx Lynx pardinus almost went extinct at the beginning of the 21st century as a result of habitat loss, persecution and the decline of its main prey, the European rabbit Oryctolagus cuniculus (Guzmán, et al., 2005; Sarmento et al., 2009). By 2008 the species was restricted to two breeding populations in Andalusia (Doñana and Cardeña-Andujár), comprising c. 200 individuals, including 60 territorial females (Simón et al., 2009). The species is categorized as Endangered on the IUCN Red List (Rodríguez \& Calzada, 2015).

In view of the imminent extinction of the Iberian lynx, a captive-breeding programme was initiated in 2003 to produce physiologically and behaviourally suitable individuals for reintroduction (Vargas et al., 2009). By 2010 $>100$ lynxes had been born in four breeding centres (three in Spain and one in Portugal).

A Spanish-Portuguese EU Life project was initiated in 2012 to identify, prepare and establish five reintroduction areas with adequate capacity for a number of self-sustaining Iberian lynx populations (Iberlince, 2016). The project and its goals were included in the Spanish-Portuguese political agreement for Iberian lynx conservation, which is supervised by the governments of both countries. Using the IUCN guidelines for reintroductions (IUCN, 2013), a reintroduction area in south-east Portugal was chosen for its habitat suitability, size and high density of rabbits. In 201510 lynxes (five males, five females) were released in this area to establish the foundation for a future population. This was the first stage of a reintroduction process that will include further releases over the next 5 years.

One of the most important aspects of any reintroduction is the development of site fidelity in areas of habitat suitable for reproduction (Devineau et al., 2011). Spatial organization and social interactions are implicated in survival, dispersal and breeding opportunities, and are therefore the foundation for a viable population (Seddon et al., 2007), and the spatial organization and social interactions established by the individuals released during the first reintroduction stage will influence the selection of release strategies in subsequent years.

Iberian lynx populations are organized in a land tenure system (Sandell, 1989), in which lynx density is regulated through territoriality and temporal avoidance, with marginal spatial overlap among same-sex individual home 


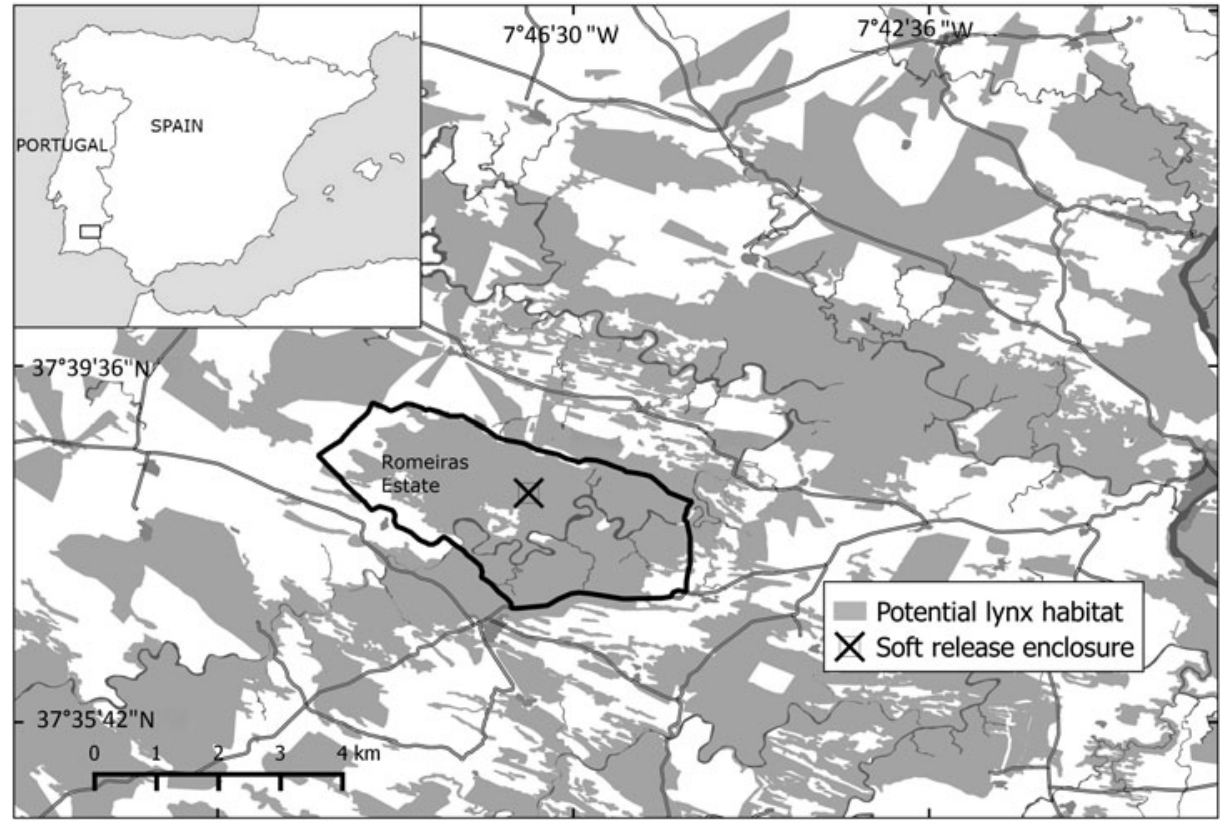

FIG. 1 Location of the Iberian lynx Lynx pardinus reintroduction area in south-east Portugal. ranges (Ferreras et al., 1997). Resident males defend their territories antagonistically against male invaders, whereas there are higher levels of overlap among females (Ferreras et al., 1997). This structure is based on a polygynous mating system in which each male usually holds an exclusive territory that is used by several females (Ferreras et al., 2004). Data available about Iberian lynx social organization and spatial distribution were obtained by monitoring freeranging lynxes via radio-telemetry (Ferreras et al., 1997; Palomares et al., 2001). In a reintroduced population the animals are captive bred and, once released, they will occupy an area without territorial borders.

We examined use of space and social interactions in 10 captive-reared Iberian lynxes during the first year after release. We hypothesized that lynxes would colonize and protect their home ranges based on a preceding rights and land tenure system (Diefenbach et al., 2006) in which the first lynxes to inhabit an area would be more successful in excluding others and sustaining the rights to that area.

\section{Study area}

The reintroduction area (c. 85,00o ha ) in south-east Portugal includes the Vale do Guadiana Natural Park, the Guadiana Site of Community Importance (Natura 2000 Network) and their surroundings (Fig. 1). The area is covered by scrublands, typical of the dry thermo-Mediterranean environment. The Myrto communis-Querceto rotundifoliae S. series is dominant, although the landscape is occasionally dominated by sub-serial stages of Genisto hirsutae-Cistetum ladaniferi, Cistetosum monspeliensis and Rhamnetum oleoidis. Scrublands are fragmented by cereal, pasturelands and forests of Pinus pinea L. and Quercus rotundifolia L. subsp. ballota. These vegetation patches occur mainly on the banks of the Guadiana riverbed and in neighbouring valleys and mountain sides. The area is bordered to the west by steppe habitat composed of cultivated grassland.

\section{Methods}

\section{Release protocol}

During 201510 lynxes were released in the Guadiana valley. They originated from three breeding centres: Silves (Portugal), Granadilla (Spain) and El Acebuche (Spain; Table 1). Lynxes were selected according to behavioural, genetic and health criteria (Godoy et al., 2009), and evaluated with a standardized veterinary protocol to assess their body condition, thus verifying their fitness and minimizing translocation risks (Martínez et al., 2009). They were fitted with collars with two tracking systems: a VHF radio tag (Sirtrack, Havelock North, New Zealand) and a global positioning system (GPS) that transmitted via the Global System for Mobile Communications (GSM; MoveTech Telemetry, Norwich, UK). The collars were programmed to transmit their locations every 12 hours. When acquiring locations, collars remained active for 3 minutes, sending 15 consecutive locations and three-dimensional accelerometer readings at a rate of $1 \mathrm{~Hz}$. Consecutive GPS fixes and accelerometer data were used as a mortality sensor (potential mortality was considered when two consecutive location readings registered the same coordinates and no movement was detected in the accelerometer data). VHF locations were obtained at least once per day through ground triangulation, using a two-element antenna (Supplementary Table S1). For each location we used 3-5 azimuths of the lynx's signal, with an 
TABle 1 Data on the 10 Iberian lynxes Lynx pardinus released in south-east Portugal (Fig. 1) during 2015.

\begin{tabular}{|c|c|c|c|c|c|c|}
\hline ID & Sex & Breeding centre & $\begin{array}{l}\text { Year of } \\
\text { birth }\end{array}$ & $\begin{array}{l}\text { Introduced to the } \\
\text { soft-release enclosure }\end{array}$ & Released in the wild & $\begin{array}{l}\text { No. of days } \\
\text { in captivity }\end{array}$ \\
\hline M01 & Male & Zarza de Granadilla & 2013 & 16 Dec. 2014 & 1 Feb. 2015 & 47 \\
\hline F01 & Female & Silves & 2012 & 16 Dec. 2014 & 1 Feb. 2015 & 47 \\
\hline M02 & Male & El Acebuche & 2013 & 7 Feb. 2015 & 25 Feb. 2015 & 18 \\
\hline F02 & Female & Silves & 2013 & 7 Feb. 2015 & 25 Feb. 2015 & 18 \\
\hline M03 & Male & El Acebuche & 2014 & 4 Mar. 2015 & 16 Apr. 2015 & 43 \\
\hline F03 & Female & Silves & 2014 & 4 Mar. 2015 & 16 Apr. 2015 & 43 \\
\hline F04 & Female & Zarza de Granadilla & 2014 & 28 Apr. 2015 & 11 May 2015 & 13 \\
\hline F05 & Female & Zarza de Granadilla & 2014 & 28 Apr. 2015 & 11 May 2015 & 13 \\
\hline M04 & Male & El Acebuche & 2014 & & 14 May 2015 & 0 \\
\hline M05 & Male & Silves & 2013 & & 14 May 2015 & 0 \\
\hline
\end{tabular}

angle of $30-120^{\circ}$ between two azimuths, within a 15 -minute period between consecutive measurements. VHF locations (usually allowing for precision of $<50 \mathrm{~m}$ ) were almost always obtained between two consecutive GSM locations. VHF locations facilitated direct observation of lynxes to confirm their condition. Both GPS fixes and VHF positions were used for the analysis, and the ratio of GSM and VHF positions varied between individuals (Supplementary Table S1).

The 10 lynxes were introduced in a 2,00o ha private estate (Romeiras), henceforth referred to as the release estate, where a 2 ha soft-release enclosure was installed (Fig. 1). The first eight lynxes were introduced using a soft-release technique. Several reintroduction programmes for similar species have used this technique, as it provides behavioural and survival advantages to the released animals (Devineau et al., 2011).

Initially two individuals were placed in the soft-release enclosure, to acclimatize them to the new environment (Table 1) before release. This procedure was repeated for three more lynx pairs, one pair at a time, before release. The first three pairs comprised a male and a female, but the fourth pair comprised two females (Table 1) because of logistical constrains in the breeding centres. Lynxes were held captive for 13-47 days (fed with wild rabbits) before being released by opening the enclosure doors. The last two males were released directly to the wild near the softrelease enclosure (Table 1).

\section{Exploratory movements}

Home range size accumulation curves were obtained by plotting the $100 \%$ minimum convex polygon against cumulative locations until the maximum home range size was reached, which marked the end of the exploratory period (Sarkar et al., 2016). During the exploratory period the approach of Sarkar et al. (2016) was used to study movement directionality away from the release sites. Distance from the release site and angular distribution were calculated for each location. We used the Rayleigh Z-test in Oriana v. 4 (Kovach, 2011) to test the uniformity of angular distribution. We tested a null hypothesis that there was directionality for all angular distributions, maintaining the release site as the mid-point. If the lynxes did not exhibit any movement directionality from the release site during the exploratory period, the null hypothesis was rejected. We calculated the mean vector of movement directionality $(\mu)$, the mean vector length $(r)$ and the circular standard deviation.

\section{Home range analysis}

The analysis was conducted for four periods, FebruaryMarch, April-May, June-July and August-December 2015. We chose 2-month periods initially to acquire at least 1 month of data for each newly released lynx, as they were released at irregular time intervals (Table 1). From August onwards all lynxes had stable home ranges.

Before estimating lynx home ranges, site fidelity and time to statistical independence were calculated for each individual (Laver \& Kelly, 2008; Supplementary Fig. S1). Absence of site fidelity and presence of exploratory behaviour were expected, particularly during the first weeks; later, the presence of conspecifics would contribute to the establishment of stable home ranges. Home range analyses were not performed in the absence of site fidelity to avoid biased home range estimates.

Site fidelity was calculated using two metrics: (1) the mean squared distance from the centre of activity, which measures dispersal of use around the home-range centroid (indicating the centre of activity), and (2) a linearity index, in which the linear distance between the start and end of a lynx's path is divided by the total distance travelled (Spencer et al., 1990). Both metrics were assessed for the real path travelled by a lynx, concerning daily and multiday movements (i.e. movements in a given direction that lasted more than one day). For example, if a lynx moved in a north-west direction for 3 days and then changed direction, we considered the 3 days as a multiday period. For each lynx 
TABLE 2 Seasonal variation, site fidelity and time to statistical independence (number of hours necessary for two consecutive locations to be time independent) in the estimated home ranges of the Iberian lynxes (Table 1) introduced in south-east Portugal (Fig. 1) during 2015.

\begin{tabular}{|c|c|c|c|c|c|}
\hline & \multirow{2}{*}{$\begin{array}{l}\text { No. } \\
\text { of fixes }\end{array}$} & \multirow{2}{*}{$\begin{array}{l}\text { Site } \\
\text { fidelity }\end{array}$} & \multirow{2}{*}{$\begin{array}{l}\text { Time to statistical } \\
\text { independence }(h)^{*}\end{array}$} & \multicolumn{2}{|c|}{ Home range $\left(\mathrm{km}^{2}\right)^{*}$} \\
\hline & & & & 95\% kernel & $50 \%$ kernel \\
\hline \multicolumn{6}{|c|}{ February-March } \\
\hline M01 & 204 & Yes & 5 & 8.07 & 0.86 \\
\hline F01 & 182 & Yes & 14 & 3.33 & 0.37 \\
\hline M02 & 76 & No & 12 & $\mathrm{NC}$ & $\mathrm{NC}$ \\
\hline \multicolumn{6}{|c|}{ April-May } \\
\hline M01 & 149 & Yes & 8 & 9.08 & 1.97 \\
\hline F01 & 96 & Yes & 9 & 6.86 & 1.75 \\
\hline M03 & 87 & Yes & 11 & 4.53 & 1.09 \\
\hline F03 & 109 & Yes & 15 & 2.94 & 0.68 \\
\hline \multicolumn{6}{|c|}{ June-July } \\
\hline M01 & 113 & Yes & 9 & 13.37 & 4.69 \\
\hline F01 & 99 & Yes & 18 & 4.25 & 0.67 \\
\hline M03 & 74 & Yes & 9 & 1.84 & 0.40 \\
\hline F03 & 177 & Yes & 12 & 0.78 & 0.21 \\
\hline F04 & 112 & No & $\mathrm{NC}$ & $\mathrm{NC}$ & $\mathrm{NC}$ \\
\hline F05 & 93 & Yes & 11 & 9.44 & 2.12 \\
\hline M04 & 111 & Yes & 10 & 2.65 & 0.83 \\
\hline M05 & 168 & Yes & 10 & 5.80 & 1.69 \\
\hline \multicolumn{6}{|c|}{ August-December } \\
\hline M01 & 124 & Yes & 11 & 12.33 & 3.26 \\
\hline F01 & 97 & Yes & 14 & 4.54 & 0.58 \\
\hline M03 & 78 & Yes & 12 & 11.36 & 5.76 \\
\hline F03 & 125 & Yes & 12 & 4.62 & 0.85 \\
\hline F04 & 119 & Yes & 12 & 22.03 & 2.19 \\
\hline F05 & 78 & Yes & 8 & 4.68 & 0.99 \\
\hline M04 & 98 & Yes & 10 & 9.23 & 2.62 \\
\hline M05 & 96 & Yes & 10 & 11.79 & 4.57 \\
\hline
\end{tabular}

${ }^{\star} \mathrm{NC}$, not calculated

and each metric, mean and standard error values were calculated using 100 randomly generated paths. We considered that a lynx exhibited site fidelity if the mean squared distance from the centre of activity or the linearity index values were significantly lower (using the $95 \%$ confidence interval) than the mean values obtained for the 100 randomly generated paths (Spencer et al., 1990).

Time to statistical independence was calculated using the method of Swihart \& Slade (1985), which defines the critical time interval after which two subsequent relocations are statistically independent. To determine time to statistical independence, Schoener's V index was calculated for increasing time intervals until the expected value under independence (i.e. 2) was reached within a given confidence interval (Swihart \& Slade, 1985). Site fidelity and time to statistical independence were estimated using the $r h r$ package (Signer \& Balkenhol, 2015) in $R$ v. 3.2.3 (R Development Core Team, 2008).

Home ranges were estimated by the fixed kernel estimator using the 95 and $50 \%$ probability contours, with a $200 \mathrm{~m}$ reference band width (smoothing factor, $h$ ), computed by least squares cross validation as suggested by Powell
(2000), using the adehabitat 1.8 .18 package (Calenge, 2006) in $R$.

\section{Individual interactions}

We quantified two types of individual interactions: static interactions, which can be defined as the spatial overlap of two individual home ranges (Millspaugh et al., 2004), and dynamic interactions, which correspond to the interdependency between two individuals' movements.

The proportion of overlap (overlap index, OI) between two overlaid home ranges (Millspaugh et al., 2004) was calculated as:

$$
\mathrm{OI}=\frac{\mathrm{HR}_{\alpha} \cap \mathrm{HR}_{\beta}}{\mathrm{HR}_{\alpha} \cup \mathrm{HR}_{\beta}}
$$

where HR is the corresponding home range area of individuals $\alpha$ and $\beta$, using the $95 \%$ contour of the kernel density. This metric was also used to quantify the amount of overlap between two consecutive home ranges of each individual in the defined 2-month periods. 

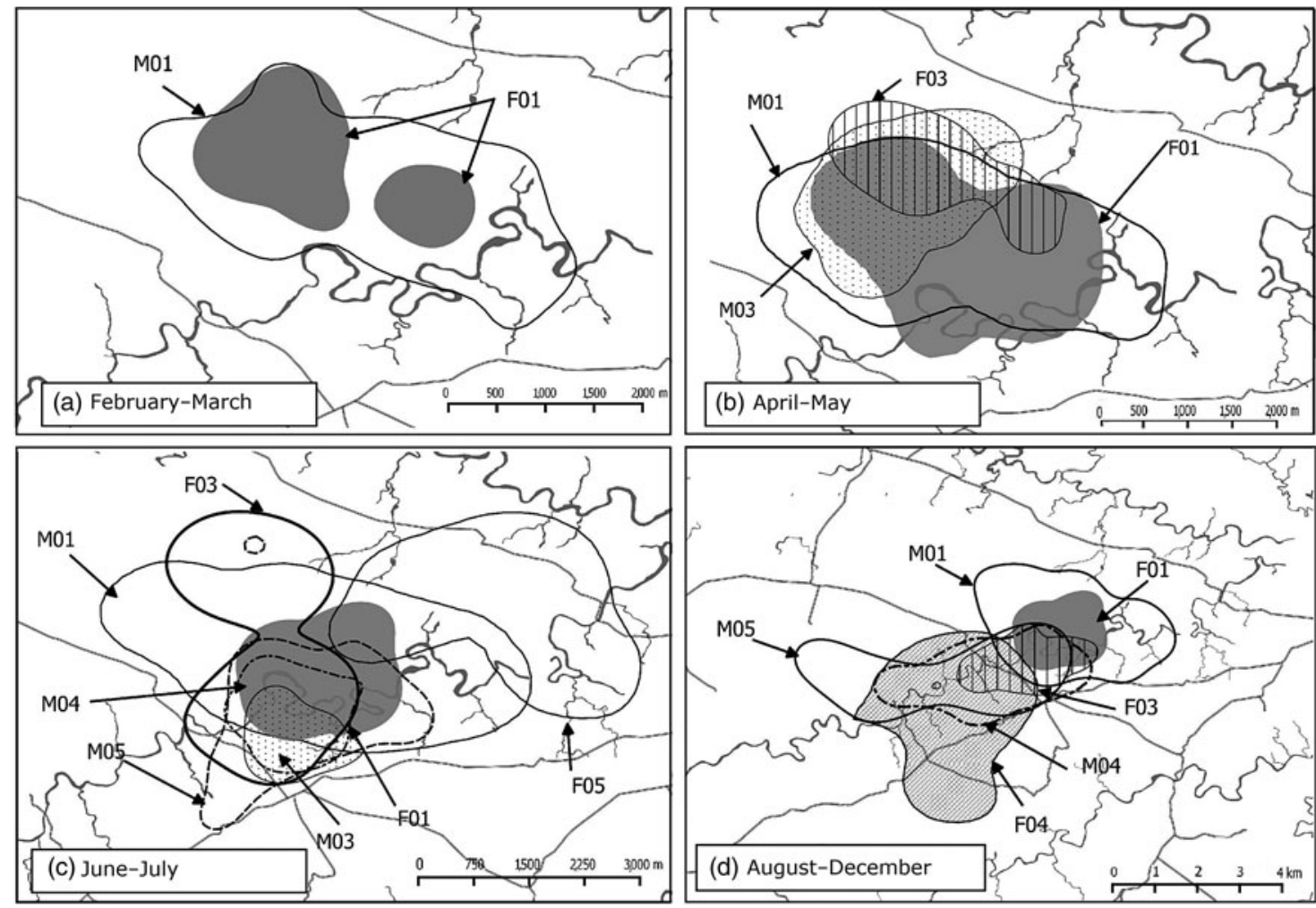

FIG. 2 Seasonal variation in the home ranges of the Iberian lynxes (Table 1) reintroduced in Portugal in 2015, using the 95\% fixed kernel estimator: (a) February-March, (b) April-May, (c) June-July, (d) August-December.
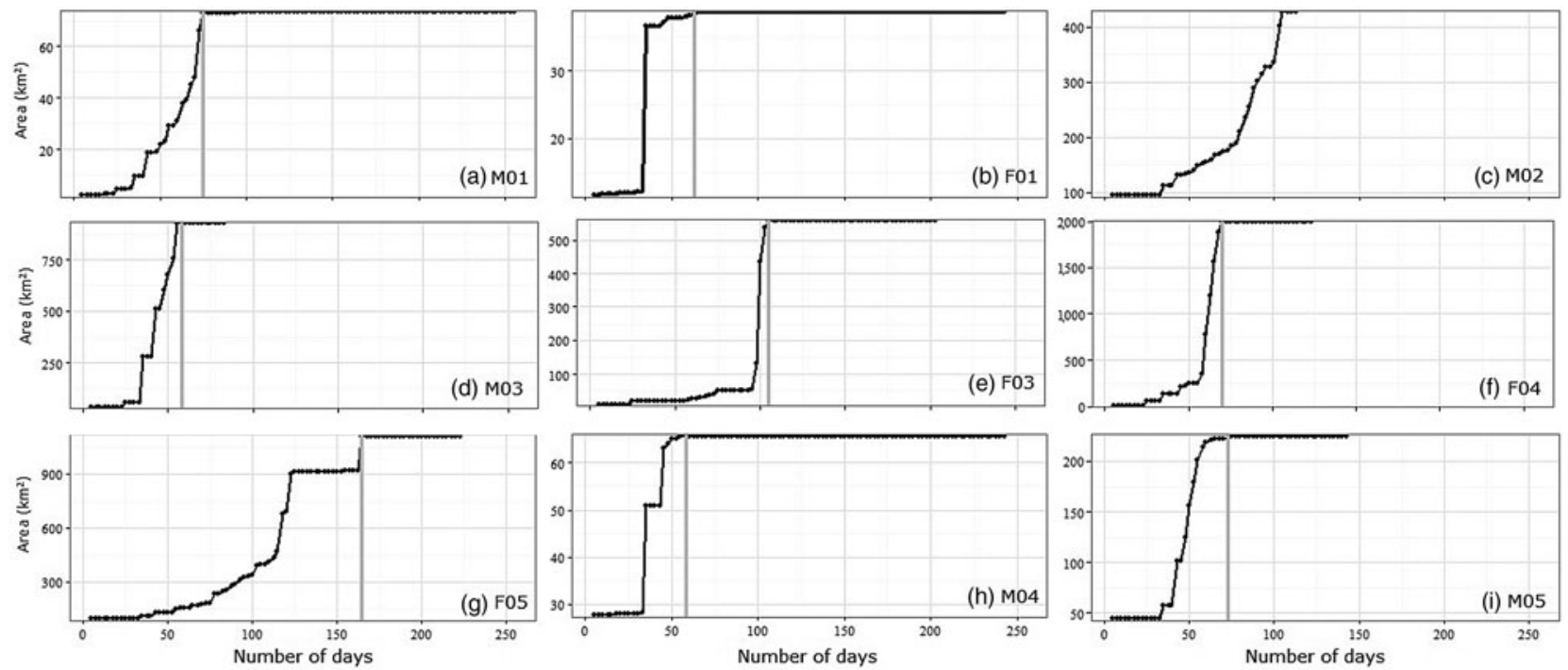

Fig. 3 The increase in the $100 \%$ minimum convex polygon of Iberian lynx locations, with the number of days of radio-tracking of individuals (Table 1) reintroduced to Portugal (Fig. 1); the vertical line represents the end of the exploratory period.

Shirabe's (2006) correlation coefficient $(\mathrm{Cr})$ was used to measure the degree of correlation in movement data between individuals. It takes the form of a multivariate Pearson product-moment correlation coefficient, and values range from -1 (negatively correlated movements) to 1 (correlated movements). Cr values near o indicate random movements in relation to the other individual. This index was analysed on a monthly basis, as no home range or site fidelity analyses were required.

Spatial and temporal interactions between each pair of lynxes were analysed using the statistics $L_{\mathrm{AA}}, L_{\mathrm{BB}}, L_{\mathrm{ixn}}$, according to Minta (1992). $L_{\mathrm{AA}}$ and $L_{\mathrm{BB}}$ are spatial interaction 

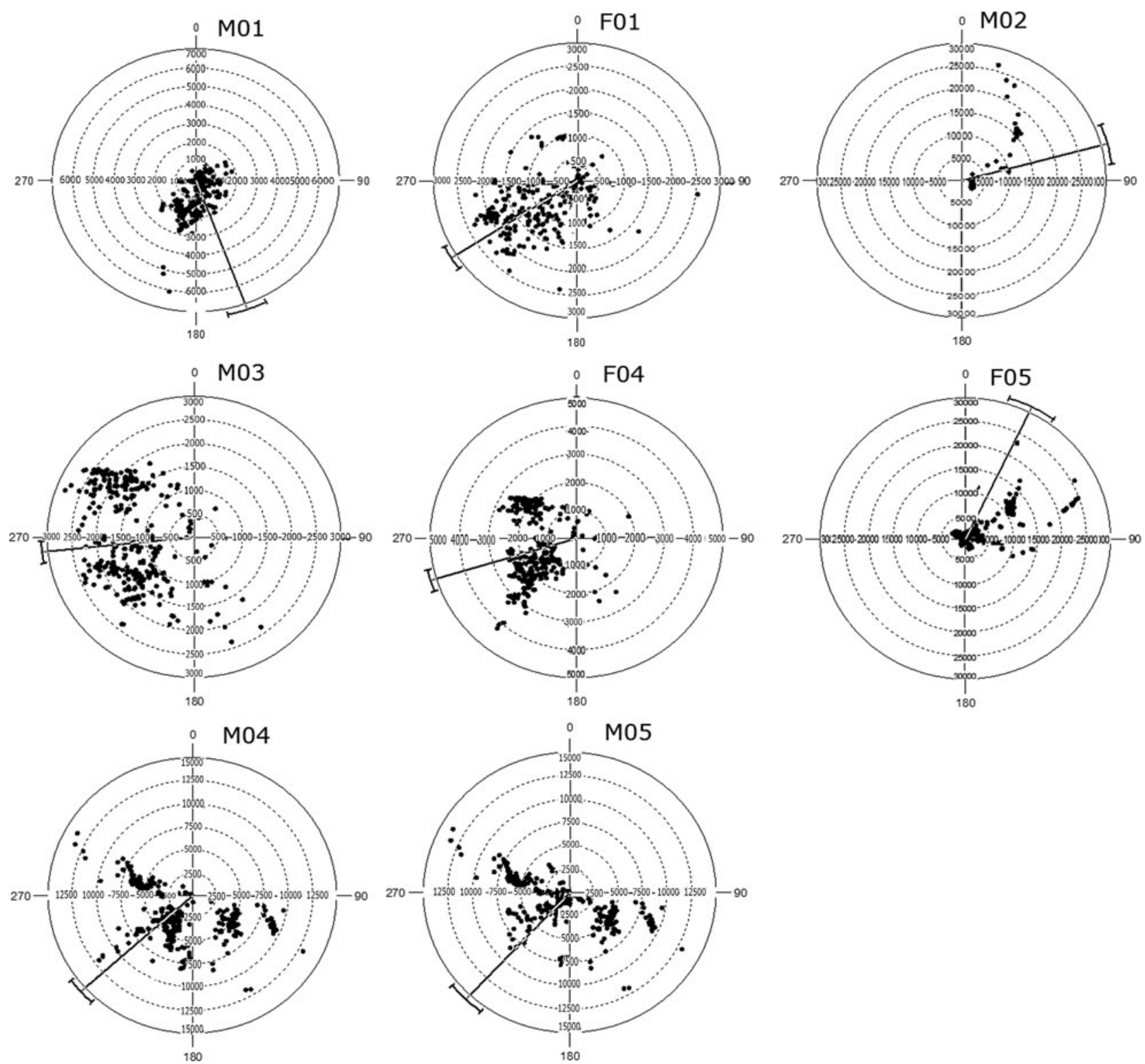

FIG. 4 Movement direction of the Iberian lynxes (Table 1) following their release in south-east Portugal (Fig. 1). The straight line represents the mean vector of directionality of movement $(\mu)$, and the bar represents the circular standard deviation.

statistics that examine how individuals $\mathrm{A}$ and $\mathrm{B}$ use their independent and mutual home range areas. $L_{\mathrm{AA}} \approx 0$ indicates that individual $\mathrm{A}$ uses the mutual area randomly, whereas $L_{\mathrm{AA}}>\mathrm{O}$ indicates spatial attraction to the mutual area, and $L_{\mathrm{AA}}<\mathrm{O}$ indicates spatial avoidance of the mutual area. The same applies to $L_{\mathrm{BB}}$ for individual $\mathrm{B}$. The $L_{\mathrm{ixn}}$ statistic is the ratio between the simultaneous use or avoidance of the mutual area and the solitary use or avoidance of the mutual area. Therefore, the $L_{\mathrm{ixn}}$ statistic is a measure of the simultaneity of use of the mutual area.

Following Atwood \& Weeks (2003), temporal interaction coefficients were pooled across time intervals, and comparisons among pair types $(\mathrm{M}|\mathrm{M}, \mathrm{M}| \mathrm{F}$ and $\mathrm{F} \mid \mathrm{F})$ were made using Kruskal-Wallis tests. When these were significant $(\mathrm{P}<0.05)$ we used Mann-Whitney $U$ statistics to determine which groups differed. Analysis of the Minta coefficients was conducted for the final period only (August-December 2015), as it was dependent on site fidelity and could be meaningful only in a relatively stable stage of social organization. All interaction analyses were performed using the wildlifeDI package in $R$ (Long, 2014).

\section{Results}

Individual histories

During February-March 2015 we released and tracked four lynxes (Table 1). Two of these exhibited site fidelity (Supplementary Fig. S1; Table 2). The first pair (Mo1 and 
Fo1) was released on 1 February. They immediately colonized the area surrounding the soft-release enclosure, and their individual seasonal home ranges had only small variations in area and temporal overlap (Fig. 2; Table 2). The area surrounding the soft-release enclosure became the core area for both individuals, as they were attracted there by the presence of the second pair, which remained enclosed for 18 days (Table 1). During that period, Mo1 and Fo1 spent a mean of $4.3 \pm$ SE 1.2 and $1.3 \pm$ SE 0.7 hours per day, respectively, circling the fence, with frequent antagonistic encounters with Mo2.

It was not possible to perform a home-range analysis of the second pair, as Mo2 did not exhibit site fidelity (Supplementary Fig. S1; Table 2) and Fo2 died on 12 March after eating poisoned bait outside the release estate. When Mo2 was released, its movements were mostly concentrated outside the home ranges of Mo1 and Fo1 (Supplementary Fig. S2). On 29 March Mo2 dispersed northwards, moving c. $9 \mathrm{~km}$ from the soft-release enclosure, where it remained at least until August, when both GPS and VHF signals were lost.

The third pair did not disperse significantly from the soft-release enclosure (maximum distance of 3.51 and $3.02 \mathrm{~km}$ for $\mathrm{Mo}_{3}$ and $\mathrm{Fo}$, respectively) despite considerable variation in their individual home ranges across time periods (Fig. 2; Table 2). Initially both animals remained in the north-west of the release estate, where they remained until the beginning of June, and then moved southwards (Fig. 2). Mo3 sustained a leg fracture at the beginning of July. He was captured promptly, and released again in October (a full account of Mo3's rehabilitation process after the injury will be presented elsewhere).

Females F04 and Fo5 differed from each other in terms of behaviour. Fo4 dispersed to the north-west (into steppe habitat), moving $13 \mathrm{~km}$ from the soft-release enclosure in 52 days (Supplementary Fig. S3). She then turned back and established a home range in the proximity of the other lynxes (Supplementary Fig. $S_{3}$ ). From August onwards Fo4 displayed site fidelity (Supplementary Fig. S1; Table 2) and became territorial, despite the relatively large home range (Fig. 2; Table 2). The other female (Fo5) did not disperse and displayed site fidelity during June-July (Fig. 2; Table 2). Originally, she established a home range north of the release estate, in the vicinity of Mo1's home range (Fig. 2). However, in mid July Fo5 dispersed northwards, up to $23 \mathrm{~km}$ from the previous home range centroid. She made an $89 \mathrm{~km}$ circular movement around the borders of the Vale do Guadiana Natural Park, and swam across the Guadiana River on two occasions (Supplementary Fig. S3). She did not return to the previous nucleus, and established a home range in the centre of the Park (Fig. 2).

The males $\mathrm{Mo}_{4}$ and Mo5, introduced by hard release, did not disperse, and established their home ranges in the southern part of the lynx nucleus (Fig. 2). Their seasonal home range was relatively stable and the main change
TABLE 3 Results of Rayleigh test of uniformity for the lynxes (Table 1) released in south-east Portugal (Fig. 1) during 2015. We tested a null hypothesis that there was directionality for all angular distributions, maintaining the release site as the mid-point. If the lynxes did not exhibit any movement uniformity from the release site during the exploratory period, the null hypothesis was rejected.

\begin{tabular}{lrlclll}
\hline & \multicolumn{3}{c}{ Rayleigh test } & & \multicolumn{3}{c}{$\begin{array}{l}\text { Circular standard } \\
\text { deviation }\left({ }^{\circ}\right)\end{array}$} & $r^{2}$ \\
\cline { 2 - 4 } Lynx & \multicolumn{1}{c}{$Z$} & $\mathrm{P}$ & $\mu\left(^{\circ}\right)^{1}$ & d & & \\
M01 & 90.37 & $<0.01$ & 159.94 & 67.629 & 0.498 \\
F01 & 169.851 & $<0.01$ & 237.459 & 50.99 & 0.673 \\
M02 & 45.226 & $<0.01$ & 75.066 & 33.761 & 0.841 \\
M03 & 208.996 & $<0.01$ & 264.078 & 43.096 & 0.754 \\
F03 & 208.382 & $<0.01$ & 253.113 & 43.208 & 0.752 \\
F04 & 64.568 & $<0.01$ & 26.011 & 75.586 & 0.419 \\
M04 & 180.434 & $<0.01$ & 215.637 & 20.47 & 0.938 \\
M05 & 102.868 & $<0.01$ & 223.16 & 71.631 & 0.458 \\
\hline
\end{tabular}

${ }^{1} \mu$, mean vector of movement directionality

${ }^{2} r$, mean vector length

between June-July and August-December was the westwards enlargement of their home range (Fig. 2; Table 2).

During the exploratory phase males covered $65-929 \mathrm{~km}^{2}$ $\left(\right.$ mean $\left.=323 \pm \mathrm{SE} 229.75 \mathrm{~km}^{2}\right)$ in 65-105 days (mean $=79.50 \pm$ SE 8.70 days) (Fig. 3). Reintroduced females explored $38-1,994 \mathrm{~km}^{2}\left(\right.$ mean $\left.=874.41 \pm \mathrm{SE} 413.65 \mathrm{~km}^{2}\right)$ in $35-125$ days (mean $=76.25 \pm$ SE 37.05 days). The duration of the exploratory period and the size of the explored area did not vary between sexes (Mann-Whitney-Wilcoxon test: $W=7.5, \mathrm{P}=1$ and $W=10, \mathrm{P}=0.686$, for males and females, respectively).

Lynxes did not exhibit any movement directionality from the release site during the exploratory period (Fig. 4). Dispersal movements varied between all individuals (Fig. 4; Table 3) despite some similarities between Fo1, Mo4 and Mo5.

During August-December a stable lynx nucleus comprising seven individuals (four male, three female) was established south-west of the soft-release enclosure. Mo3 was re-released at the end of October, following recovery from the leg fracture, and went on to establish a home range north-west of the soft-release enclosure, displaying site fidelity (Supplementary Fig. S1; Table 2).

Considering only August-December 2015, there were no differences between mean home range sizes of males and females (11.18 \pm SE 1.36 and $9.87 \pm \mathrm{SE} 8.71 \mathrm{~km}^{2}$, respectively; Mann-Whitney-Wilcoxon test: $\mathrm{W}=4, \mathrm{P}=0.343$ ).

\section{Static interactions}

Fo1|Mo1 was the only dyad analysed for all four periods. They displayed high overlap ( $>0.4$ ) of their home ranges (Fig. 5; Table 4). There was also high overlap between the home range of $\mathrm{Mo}_{4}$ and those of $\mathrm{Fo}_{3}$, Fo4 and Fo5, particularly during August-December (Fig. 5; Table 4), when Mo4 was the only male whose home range overlapped with those 


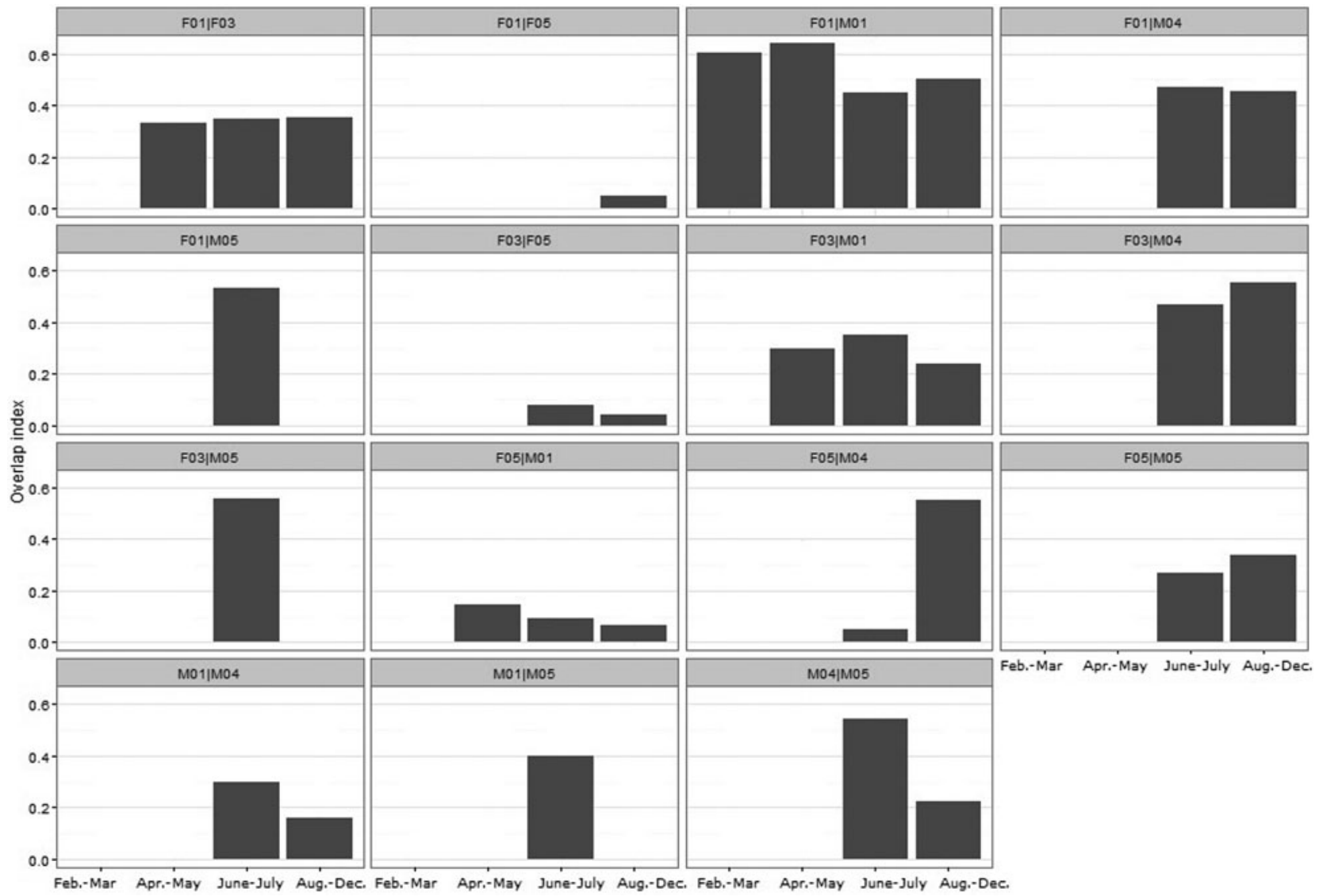

FIG. 5 Seasonal home range overlap index for Iberian lynx dyads released in Portugal (Fig. 1) in 2015.

TABLE 4 Home range overlap proportions for each lynx (Table 1) introduced in south-east Portugal (Fig. 1) during 2015 during two consecutive periods.

\begin{tabular}{|c|c|c|c|c|c|c|c|c|c|}
\hline & M01 & F01 & M02 & M03 & F03 & F04 & F05 & M04 & M05 \\
\hline Feb.-Mar./Apr.-May & 0.78 & 0.67 & 0.00 & & & & & & \\
\hline Apr.-May/June-July & 0.65 & 0.61 & 0.82 & 0.01 & 0.29 & 0.00 & 0.00 & & \\
\hline June-July/Aug.-Dec. & 0.79 & 0.67 & & 0.11 & 0.37 & 0.29 & 0.00 & 0.52 & 0.57 \\
\hline 1st season/last season & 0.67 & 0.45 & & 0.13 & 0.00 & 0.00 & 0.00 & 0.52 & 0.57 \\
\hline
\end{tabular}

of three females. Mo1 overlapped with two females and Mo5 overlapped only with Fo5.

Considering the last period, the mean overlap of male home ranges was $0.18 \pm \mathrm{SE} 0.23$, and of female home ranges $0.17 \pm$ SE 0.37 ; the mean intersexual home range overlap was $0.35 \pm$ SE 0.41 . There were no significant differences in seasonal overlap of home ranges within pair types $(\mathrm{F}|\mathrm{F}, \mathrm{F}| \mathrm{M}$ and $\mathrm{M} \mid \mathrm{M}$; Kruskal-Wallis test: $\chi_{2}^{2}=0.589, \mathrm{P}=0.745$ ).

\section{Dynamic interactions}

Dynamic interactions were evaluated for the final population nucleus, comprising Mo1, Mo4 and Mo5, and Fo1, Fo3 and Fo5. Mo3 was excluded to avoid biased results. Considering all possible dyad combinations, Mo1|Mo5 was excluded because there was no contact between their home ranges.
Shirabe's (2006) correlation coefficient indicated that several dyads had positively or negatively correlated movements (Fig. 6). Positive interactions were observed between Fo1|Mo1, Fo1|Mo4 and Fo5|Mo4 during August-December. Negative interactions were detected for Mo1|Mo4 and Mo4| Mo5 (Fig. 6). In general, movements of female dyads were uncorrelated.

During August-December none of the dyads showed significant simultaneous attraction to their home range overlap area (Fig. 7). Two female-male pairs (Fo3 $\mid \mathrm{Mo1}$ and Fo5 Mo4) exhibited non-simultaneous attraction to the overlap area, and four female-male pairs (Fo1|Mo4, Fo3|Mo4, Fo3| Mo5 and Fo5|Mo5) exhibited only male attraction to the overlap area (Fig. 7). Male avoidance of the overlap area was observed in dyad Fo5|Mo1 (Fig. 7), possibly because of the low home range overlap. Among females no attraction or 

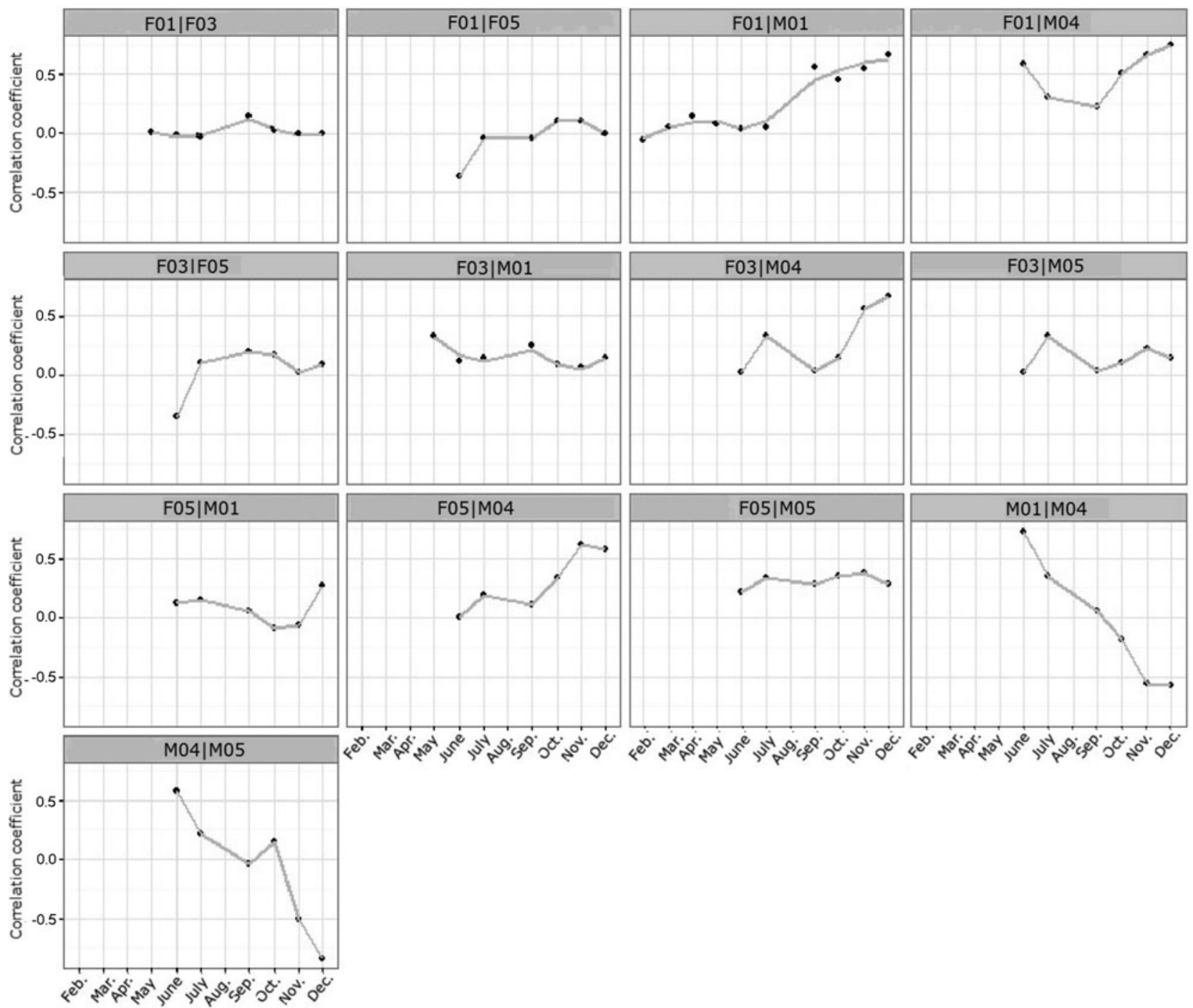

Fig. 6 The degree of correlation in movement data between Iberian lynx dyads released in Portugal (Fig. 1) in 2015, according to Shirabe's (2006) correlation coefficients.

repulsion was observed in either spatial $\left(L_{\mathrm{AA}}\right.$ and $\left.L_{\mathrm{BB}}\right)$ or temporal interactions $\left(L_{\mathrm{ixn}}\right)$. Considering males only, there were two cases of significant attraction of one individual to the overlap area (Mo4 in relation to Mo1 and Mo5 in relation to Mo4), but never simultaneously (i.e. Mo4's attraction in relation to Mo1 did not occur in the same period as Mo5's attraction in relation to Mo4). Coefficients of temporal interaction for pair types differed significantly (Kruskal-Wallis test: $\chi_{2}^{2}=7.471, P=0.024$ ), with coefficients for male-male pairs being substantially lower than coefficients for malefemale and female-female pairs (Mann-Whitney-Wilcoxon test: $W=319.5, \mathrm{P}=0.045$ ).

\section{Discussion}

The Iberian lynx reintroduction programme in Portugal was not planned primarily as a trial to evaluate reintroduction strategies but was constrained by the enclosure capacities of the breeding centres. When more space was needed for newborn lynxes, the individuals previously selected for the reintroduction programme were translocated.

All stages involved in releasing animals into a new environment can cause distress to the animals (Letty et al., 2007), and a negative post-release effect, especially on body condition, has been observed not only in Iberian lynxes (Simón et al., 2009) but also in other felines (Devineau et al., 2011; Sarkar et al., 2016). In this context, the soft-release enclosure could be critical to acclimatize lynxes to the wild, even though we were not expecting that all individuals would remain in the nearby area because of the territorial behaviour of previously released individuals. Only the first pair of released lynxes remained in the nearby area; all others moved further away from the soft-release enclosure, probably as an effect of competition. Although several lynxes remained in the vicinity of 

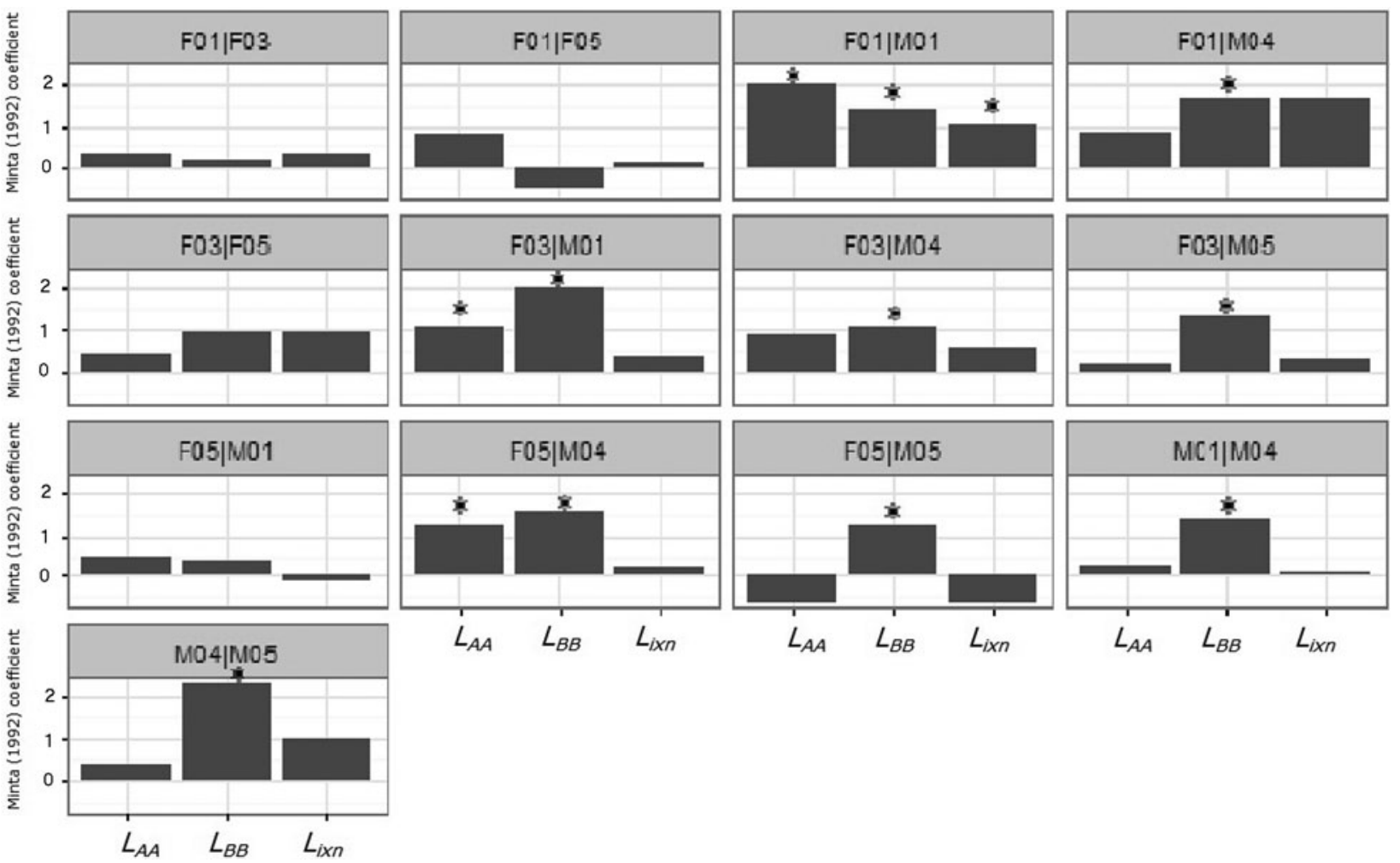

Fig. 7 Minta (1992) coefficients $\left(L_{\mathrm{AA}}, L_{\mathrm{BB}}, L_{\mathrm{ixn}}\right)$ for Iberian lynx dyads released in Portugal (Fig. 1) in 2015. $\mathrm{L}_{\mathrm{AA}}$ and $\mathrm{L}_{\mathrm{BB}}$ are spatial interaction statistics that examine how individuals (A and B) use their independent and mutual home range areas. The $\mathrm{L}_{\mathrm{ixn}}$ statistic depends on the ratio of simultaneous use (and avoidance) of the mutual area and solitary use or avoidance of the mutual area. ${ }^{\star}$ indicates significant values with $\mathrm{P}<0.05$.

the first pair's home range, in time a social organization was established (Fig. 2), which had many similarities to the organization described for wild populations (Ferreras et al., 1997; Gil-Sánchez et al., 2011; López-Parra et al., 2012), including low home range overlap between males (c. 15\%) and between females (c. 22\%), female home ranges of $2.5-6.5 \mathrm{~km}^{2}$, and an intersexual home range overlap of c. 40\% (Ferreras et al., 1997; Gil-Sánchez et al., 2011; López-Parra et al., 2012). However, these similarities are not always observed in a reintroduction context: female-female overlap was practically the same as male-male overlap in several Spanish reintroduction areas (Miguel Simón, pers. comm.). Further detailed analyses are required to investigate potential differences in the social organization of wild and reintroduced lynx populations.

The movement patterns observed during the last phase of the study are also indicators of social organization, particularly avoidance between males, correlated male-female movements, and male attraction towards the areas where their home ranges overlapped with those of females. This scenario is typical of feline populations (Schmidt et al., 1997; Elbroch et al., 2015) and is an indicator of the reintroduction's success during the first year.

By the end of 2015 the observed mortality of reintroduced lynxes was $10 \%$ and there was a relatively stable nucleus of four males and three females, each with overlapping home ranges with at least one other individual. From January 2016 onwards it was not possible to continue the analysis of social interactions using the same type of data, as the tags' batteries were no longer operating. Since then we have been using camera-trapping to monitor the individuals released in 2015.

Camera-trapping confirmed lynx reproduction in June 2016, when Fo1 was photographed with one cub and Fo5 was photographed with four cubs. By the end of 2016 all juveniles were still alive. These were the first lynx reproduction events recorded in Portugal in $>25$ years. The presence of cubs, and their survival, confirms the suitability of the area chosen for lynx reintroduction. The social organization that the lynxes established in the reintroduction area facilitated stable home ranges, patrolling behaviour and intersexual encounters.

Understanding exploratory movements and home range characteristics is crucial within the reintroduction context, as they influence survival, fitness and overall success (Sarkar et al., 2016). The soft-release enclosure contributed to the first pair settling nearby and it also had an attractive effect on the second pair. The soft-release enclosure was probably a determinant in establishing the population nucleus. Not all released lynxes were expected to stay in the study area, and three cases of dispersal were observed. Mo2 probably dispersed because of the negative effect of 
Mo1 and Fo2 near the release site. Fo5 initiated an exploratory movement without any apparent cause after maintaining a relatively stable home range for 2 months. In 2016, Mo5 dispersed towards the Donãna National Park, where it was captured by the Spanish Life project team. Before dispersing, this individual displayed a stable home range, and causes of dispersal were not determined. Confirming dispersal between the Portuguese reintroduction area and the lynx population in Doñana was an important finding, particularly as Doñana is surrounded by man-made barriers that impede movements, and thus connections to other lynx populations are possible only through narrow bottlenecks (Blazquez-Cabrera et al., 2016).

The lynxes in our study did not exhibit any directional movement from the release site during the exploratory period. All individuals had an exploration phase, in which most visited areas of unsuitable habitat (e.g. steppe), probably searching for suitable resources.

The establishment of home ranges and social interactions, the occurrence of reproduction, and juvenile survival indicate the reintroduction programme's success and confirm the availability of suitable habitat in the reintroduction area (Sarkar et al., 2016). Predictive models had already demonstrated the suitability of the study area for lynx reintroduction, and the knowledge obtained during the first year confirmed the results of these models. Other individuals will be released, until 2020, by hard-release techniques in unoccupied areas surrounded by occupied territories, which should promote strong social ties within the resident population, to prevent dispersal. Intensive post-release monitoring continues, to increase survival and produce critical information for population management by assuring that released individuals are in good body condition and in areas where there is no poaching. To some extent our findings confirm the preceding rights and land tenure system based on territorial defence against conspecifics (Diefenbach et al., 2006), although more data from the reintroduction programme will be required to confirm this, as more individuals are released.

\section{Acknowledgements}

This work was supported by the European Union (Life+ project Recovery of the historical distribution for Iberian lynx (Lynx pardinus) in Spain and Portugal: LIFE1oNAT/ ES/570), the Centre for Environmental and Marine Studies UID/AMB/50017 (Fundação para a Ciência e Tecnologia/ Ministério da Educação e Ciência through national funds and FEDER PT2020, Compete 2020), and the Fundação para a Ciência e Tecnologia (Grant SFRH/BPD/72311/ 2010). We thank the Research Centre in Biodiversity and Genetic Resources/Porto University, Ana Serronha, Elisa Maio, Andreola Velleryd and Nuno Santos for collecting data on a female lynx.

\section{Author contributions}

PS conducted field work, performed the statistical analysis and wrote most parts of the article. CC conducted field work, constructed the radio tags and contributed to the writing of the article. CE contributed to the writing of the article and conducted an intensive review of the work. JPS developed the radio-tag technology and conducted an intensive review of the work.

\section{References}

Aтwood, T.C. \& Weeks, H.P. (2003) Spatial home-range overlap and temporal interaction in eastern coyotes: the influence of pair types and fragmentation. Canadian Journal of Zoology, 81, 1589-1597.

Blazquez-Cabrera, S., Gastón, A., Beier, P., Garrote, G., SIMÓN, M.A. \& SAURA, S. (2016) Influence of separating home range and dispersal movements on characterizing corridors and effective distances. Landscape Ecology, 31, 2355-2366.

Calenge, C. (2006) The package adehabitat for the R software: a tool for the analysis of space and habitat use by animals. Ecological Modelling, 197, 516-519.

Devineau, O., Shenk, T.M., Doherty JR, P.F., White, G.C. \& KAHN, R.H. (2011) Assessing release protocols for Canada lynx reintroduction in Colorado. The Journal of Wildlife Management, 75, 623-630.

Diefenbach, D.R., Hansen, L.A., Warren, R.J. \& Conroy, M.J. (2006) Spatial organization of a reintroduced population of bobcats. Journal of Mammalogy, 87, 394-401.

Elbroch, L.M., Lendrum, P.E., Quigley, H. \& Caragiulo, A. (2015) Spatial overlap in a solitary carnivore: support for the land tenure, kinship or resource dispersion hypotheses? Journal of Animal Ecology, 85, 487-496.

Ferreras, P., Beltrán, J.F., Aldama, J.J. \& Delibes, M. (1997) Spatial organization and land tenure system of the endangered Iberian lynx (Lynx pardinus). Journal of Zoology, 243, 163-189.

Ferreras, P., Delibes, M., Palomares, F., Fedriani, J.M., Calzada, J. \& Revilla, E. (2004) Proximate and ultimate causes of dispersal in the Iberian lynx Lynx pardinus. Behavioural Ecology, 15, $31-40$.

Gil-Sánchez, J.M., Moral, M., Bueno, J., Rodríguez-Siles, J., Lillo, S., Pérez, J. et al. (2011) The use of camera trapping for estimating Iberian lynx (Lynx pardinus) home ranges. European Journal of Wildlife Research, 57, 1203-1211.

Godoy, J., Casas-Marce, M. \& Fernández, J. (2009) Genetic issues in the implementation of the Iberian lynx ex situ programme. In Iberian Lynx Ex Situ Conservation: An Interdisciplinary Approach (eds A. Vargas, C. Breitenmoser \& U. Breitenmoser), pp. 74-85. Fundación Biodiversidad, Madrid, Spain.

Guzmán, N., Gárcia, F., Garrote, G., Ayala, R. \& Iglesias, C. (2005) El lince ibérico (Lynx pardinus) en España y Portugal. Censo-diagnóstico de sus poblaciones. Dirección General para la Biodiversidad, Madrid, Spain.

IberLince (2016) Http://www.iberlince.eu [accessed 21 March 2017]. IUCN (2013) Guidelines for Reintroductions and Other Conservation Translocations. IUCN Species Survival Commission, Gland, Switzerland.

Kovach, W.L. (2011) Oriana-Circular Statistics for Windows, v. 4. Kovach Computing Services, Pentraeth, UK.

Laver, P.N. \& Kelly, M.J. (2008) A critical review of home range studies. The Journal of Wildlife Management, 72, 290-298. 
Letty, J.S., Marchandeau, S. \& Aubineau, J. (2007) Problems encountered by individuals in animal translocations: lessons from field studies. Écoscience, 14, 420-431.

LoNG, J.A. (2014) wildlifeDI: A suite of R tools for exploring dynamic interaction patterns in wildlife telemetry data. $\mathrm{R}$ package vignette. Version 0.2.

López-Parra, M., Fernández, L., Ruiz, G., Gil-Sánchez, J.M., Simón, M.A., López, G. \& Sarmento, P. (2012) Change in demographic patterns of the Doñana Iberian lynx Lynx pardinus: management implications and conservation perspectives. Oryx, 46, 403-413.

Martínez, F., López, G., Pastor, J., Zorrilla, I., Muñoz, A., GARCíA, I. \& VARGAS, A. (2009) Integrating health issues into the conservation of the Iberian lynx. In Iberian Lynx Ex Situ Conservation: An Interdisciplinary Approach (eds A. Vargas, C. Breitenmoser \& U. Breitenmoser), pp. 166-183. Fundación Biodiversidad, Madrid, Spain.

Millspaugh, J.J., Gitzen, R.A., Kernohan, B.J., Larson, M.A. \& Clay, C.L. (2004) Comparability of three analytical techniques to assess joint space use. Wildlife Society Bulletin, 32, 148-157.

Minta, S.C. (1992) Tests of spatial and temporal interaction among animals. Ecological Applications, 2, 178-188.

Palomares, F., Delibes, M., Revilla, E., Calzada, J. \& Fedriani, J. M. (2001) Spatial ecology of Iberian lynx and abundance of European rabbits in south-western Spain. Wildlife Monographs, 148, 1-36.

Powell, R.A. (200o) Animal home ranges and territories and home range estimators. In Research Techniques in Animal Ecology (eds L. Boitani \& T.K. Fuller), pp. 65-103. Columbia University Press, New York, USA.

R Development Core Team (2008) R: A Language and Environment for Statistical Computing. R Foundation for Statistical Computing, Vienna, Austria.

Rodríguez, A. \& Calzada, J. (2015) Lynx pardinus. In The IUCN Red List of Threatened Species 2015: e.T12520A50655794. Http://dx.doi. org/10.2305/IUCN.UK.2015-2.RLTS.T12520A50655794.en [accessed 20 March 2017].

SANDELL, M. (1989) The mating tactics and spacing patterns of solitary carnivores. In Carnivore Behavior, Ecology and Evolution (ed. J.L. Gittleman), pp. 164-182. Cornell University Press, Ithaca, USA.

Sarkar, M.S., Ramesh, K., Johnson, J.A., Sen, S., Nigam, P., Gupta, S.K. et al. (2016) Movement and home range characteristics of reintroduced tiger (Panthera tigris) population in Panna Tiger Reserve, central India. European Journal of Wildlife Research, 62, 537-547.

Sarmento, P., Cruz, J., Monterroso, P., Tarroso, P., Ferreira, C., Negrões, N. \& Eira, C. (2009) Status survey of the critically endangered Iberian lynx Lynx pardinus in Portugal. European Journal of Wildlife Research, 55, 247-253.

Schmidt, K., Jędrzejewski, W. \& Okarma, H. (1997) Spatial organization and social relations in the Eurasian lynx population in Białowieża Primeval Forest, Poland. Acta Theriologica, 42, 289-312.

Seddon, P.J., Armstrong, D.P. \& Maloney, R.F. (2007) Developing the science of reintroduction biology. Conservation Biology, 21, 303-312.

Shirabe, T. (2006) Correlation analysis of discrete motions. In GIScience 2006 (eds M. Raubal, H.J. Miller, A.U. Frank \& M.F. Goodchild), pp. 370-382. Springer-Verlag, Berlin, Germany.

Signer, J. \& Balkenhol, N. (2015) Reproducible home ranges (rhr): a new, user-friendly R package for analyses of wildlife telemetry data. Wildlife Society Bulletin, 39, 358-363.

Simón, M.A., Cadenas, R., Gil-Sánchez, J.M., López-Parra, M., Gárcia, J., Fernández, L. \& López, G. (2009) Conservation of free-ranging populations of Iberian lynx in Andalusia. In Iberian Lynx Ex Situ Conservation: An Interdisciplinary Approach (eds A. Vargas, C. Breitenmoser \& U. Breitenmoser), pp. 42-55. Fundación Biodiversidad, Madrid, Spain.

Spencer, S.R., Cameron, G.N. \& SwiHart, R.K. (1990) Operationally defining home range: temporal dependence exhibited by hispid cotton rats. Ecology, 71, 1817-1822.

Swihart, R.K. \& SLAde, N.A. (1985) Testing for independence of observations in animal movements. Ecology, 66, 1176-1184.

Vargas, A., Sánchez, I., Martínez, F., Rivas, A., Godoy, J., Roldan, E. \& BReitenmoser, U. (2009) Interdisciplinary methods in the Iberian lynx conservation breeding programme. In Iberian Lynx Ex Situ Conservation: An Interdisciplinary Approach (eds A. Vargas, C. Breitenmoser \& U. Breitenmoser), pp. 56-71. Fundación Biodiversidad, Madrid, Spain.

\section{Biographical sketches}

PeDro SARmento is a wildlife biologist whose research is focused on the recovery of threatened species, population ecology and Iberian lynx conservation. He is a member of the IUCN Cat Specialist Group. Carlos Carrapato is a wildlife biologist working on ecosystem and species management in the south of Portugal. He is currently collaborating on international projects focused on the Iberian lynx and the imperial eagle. CATARINA EIRA is a wildlife biologist with a particular focus on ecotoxicology and helminth-vertebrate host ecology. Jo Ão PA ULO SILVA's research is focused on animal movement, radiotracking technology and bird ecology. 